\title{
Barbiturate dependence in mice induced by a simple short-term oral procedure*
}

\author{
J. K. BELKNAP, STEPHANIE WADDINGHAM, and GENE ONDRUSEK \\ University of Texas at Austin. Austin. Texas 78712
}

\begin{abstract}
A procedure for inducing phenobarbital (PB) dependence in mice is presented, using an adulterated milled diet. Marked withdrawal symptoms, including convulsions, were readily produced. In comparison with $\mathrm{C} 57 \mathrm{BL} / 6 \mathrm{~J}$ mice, DBA/2J mice showed markedly greater intoxication and withdrawal, while consuming less PB during the same period. Thus, DBA/2J animals showed a heightened sensitivity to PB dependence than did C57BL/6J animals.
\end{abstract}

In recent years, a number of reports have appeared which demonstrate methods useful in inducing physical drug dependence in laboratory rodents. The operational criterion for physical dependence is the observation of readily discernible withdrawal symptoms following the cessation of drug administration. This criterion has been met for alcohol (Mello, 1973), barbiturates (Essig, 1970; Freund, 1971), and morphine (Schuster \& Thompson, 1969: Collier et al, 1972; Way et al, 1968) to the extent that hyperreactivity and convulsions have been reliably produced. These methods offer much promise for future work involving drug tolerance and dependence.

Unfortunately, most of these techniques require a means of extended drug administration which is stressful or physically debilitating to the animals. Further, the drug must often be administered over a long period of time (weeks or months), which greatly increases the time and labor required. The technique reported below largely overcomes both of these difficulties with regard to physical dependence on barbiturates (phenobarbital) and offers a promising animal model for the study of the dependence process.

\section{METHOD}

Thirty male mice (15 $\mathrm{C} 57 \mathrm{BL} / 6 \mathrm{~J}$ and $15 \mathrm{DBA} / 2 \mathrm{~J})$ were allowed to adjust to our laboratory regimen for 3 weeks following their receipt from the Jackson Laboratories, Bar Harbor, Maine. Yellow pine shavings served as bedding. At 15 weeks of age, all animals were housed singly and placed on a milled food diet (Purina Lab Chow) dispensed from a glass jar $(48 \times 55 \mathrm{~mm})$ with a $21-\mathrm{mm}$ hole drilled in the center of a metal screw-on cap. After 2 days, the experiment began with the introduction of phenobarbital (PB) (Sigma Chemical Co.), thoroughly mixed with the milled diet $(2.5 \mathrm{mgPB}$ per gram diet), to 20 of the animals (PB group) for $5-2 / 3$ days. The control group $(\mathrm{N}=10)$ continued to receive the plain diet only. Both groups were composed of equal numbers of each inbred strain. Withdrawal was accomplished by substituting plain diet for the PB-adulterated diet in the PB group on the morning of the 6 th day. Body weight and food consumption were routinely assessed at 2 p.m. each day. During PB administration, the degree of

*This work was supported by NSF-USDP Grant GU-1598 awarded to John K. Belknap, University of Texas at Austin, Austin, Texas. intoxication was assessed for each animal at 8 a.m. ( $1 \mathrm{~h}$ after light onset) and 8 p.m. ( $1 \mathrm{~h}$ before light off set). A grasping reflex ("pencil") test was administered based on the number of seconds the animal could remain hanging from a horizontally suspended pencil $10 \mathrm{in}$. above the cage bedding. The longest time in three attempts was recorded and a score of 10 (the maximum) assigned to animals who could not hold themselves on the pencil at all. Intermediate scores were determined by subtracting their times (in seconds) from 10 . Hence, high scores indicate high degrees of neuromuscular impairment. Following this, each animal was observed for $1 \mathrm{~min}$, with occasional prodding, and an intoxication score assigned as follows (after Freund, 1971): 0-no appreciable behavioral effects: 1 -pronounced staggering and impaired gait; 2 -falling on side or back; 3 -impaired righting reflex (more than $2 \mathrm{sec}$ required to regain righting when placed on back). Scores intermediate to these were occasionally given.

Following withdrawal, the animals were observed at approximately $5-\mathrm{h}$ intervals for $2 \frac{1}{2}$ days. Each animal was suspended by the tail for $10 \mathrm{sec}$, returned to his cage, and observed for $1 \mathrm{~min}$ with occasional prodding. A withdrawal score was then assigned as follows: 0 -no appreciable effects compared with controls; 1 -the presence of one or more of the following: marked tremor, pronounced "jumpiness" when touched, tail arched forward; 2 -wild running, convulsions.

\section{RESULTS}

Animals of the $D B A / 2 J$ strain showed markedly greater intoxication than the $\mathrm{C} 57 \mathrm{BL} / 6 \mathrm{~J}$ mice throughout the period of $\mathrm{d}$ ug administration, as determined by the intoxication score $(\mathrm{p}<.001$ sign test $)$ and the pencil test ( $p<.01$, sign test) (Fig. 1). Despite this, the C57BL/6J animals consumed $22 \%$ more phenobarbital over the full 5 days than did the DBA/2J mice $(\mathrm{p}<.01$, two-tailed $t$ test) (Fig. 1). This held true for the 6th day as well (not shown) until the time of withdrawal (16 $\mathrm{h}$ into the 6th day).

Both strains showed a sizable increase in drug consumption over days (Days 1 and 2 vs 4 and 5 , $p<.01$, two-tailed $t$ test), while their levels of intoxication decreased slightly (Fig. 1). Thus, both strains achieved a considerable degree of acquired tolerance to the drug effects.

Mean body weight was initially the same for both strains (26.2 g, PB group). Body weight loss during the time of PB admimistration averaged $11 \%$ and $0 \%$ for the 


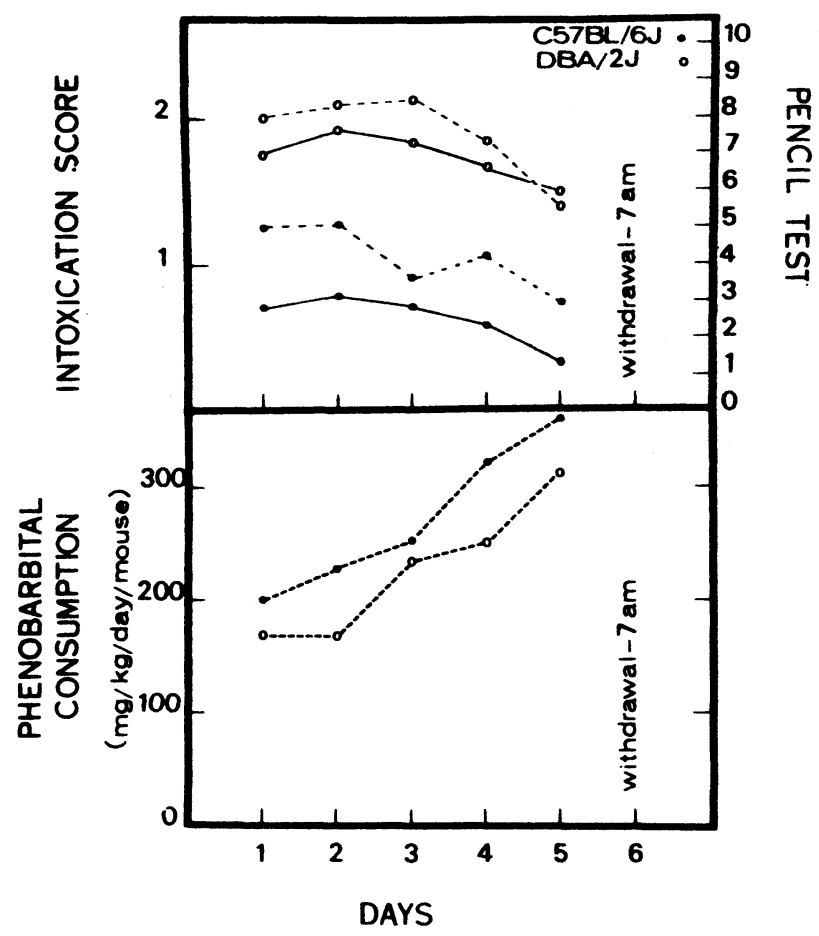

Fig. 1. The upper graph depicts the intoxication score (solid line) and the pencil test (dashed line) for the C57BL/6J mice (solid circles) and DBA/2J mice (open circles). Each point represents the daily mean based on two observation periods ( 8 a.m. and 8 p.m.) per day. The control group (not shown) consistently averaged 0 on the intoxication score and less than 1 on the pencil test. The lower graph shows the corresponding drug consumption data during the same period.

$\mathrm{DBA} / 2 \mathrm{~J}$ and $\mathrm{C57BL} / 6 \mathrm{~J}$ mice, respectively. The controls maintained a constant body weight during this inverval.

Withdrawal symptoms were markedly more severe for the $\mathrm{DBA} / 2 \mathrm{~J}$ mice compared to the $\mathrm{C} 57 \mathrm{BL} / 6 \mathrm{~J}$ mice (Fig. 2) as evidenced by the summed (over all observations) withdrawal scores ( $p<.05$, sign test), and the higher number of convulsions and/or wild running observed (Fig. 2). Convulsions were usually of the clonic-tonic type lasting less than $1 \mathrm{~min}$. Both strains showed a $10 \%$ loss in body weight during the first day of withdrawal. A gradual recovery to prewithdrawal levels occurred during the next 3 days.

\section{DISCUSSION}

Despite the significantly smaller drug consumption, the DBA/2J mice showed a greater liability to intoxication and physical dependence to phenobarbital than did C57BL/6J mice. Thus, DBA/2J mice were highly susceptible to both of these drug effects, while mice of the $\mathrm{C} 57 \mathrm{BL} / 6 \mathrm{~J}$ strain were relatively resistant. Since all animals were reared and treated in the same manner, such inbred strain differences provide presumptive evidence of genetic determination in the intoxication and dependence processes. The ready availability of animals which differ so markedly on these traits could be a valuable tool for future investigations (Belknap, in press).

The most frequently employed method for producing barbiturate dependence in laboratory animals has been that developed by Crossland and Leonard (1963). Sodium barbital, in gradually increasing doses, is dissolved in the drinking water and continuously administered for periods ranging from 4 weeks (Leonard, 1967, 1968; Blagoeva et al, 1972) to several months (Essig, 1966; Waters \& Okamoto, 1972, 1973). The drug solution is often supplemented with saccharin to partially disguise the aversive taste. The method reported here achieves comparable levels of dependence in a relatively short time (6 days), and the animals show little or no reluctance for ingesting the drug. Experiments in our laboratory (unpublished) using a two-jar choice situation (plain diet vs PB diet) indicate no avoidance of the PB diet in either naive or previously dependent and withdrawn animals.

Freund (1971) reported dependence production in C57BL/6J mice by administering an elixir of PB (U.S.P.) mixed with a liquid diet (Metrecal) for up to 6 days. While a highly efficient method, the PB can be expected to exist largely as a suspension, necessitating frequent shaking in order to obtain precise PB consumption data. Ethanol (1\% final concentration) was also present in the diet.

The availability of these oral PB methods should make research on a wider scale more feasible than has hitherto been possible. For example, the relatively short time period required readily lends itself to experimental manipulations on the development of drug dependence.

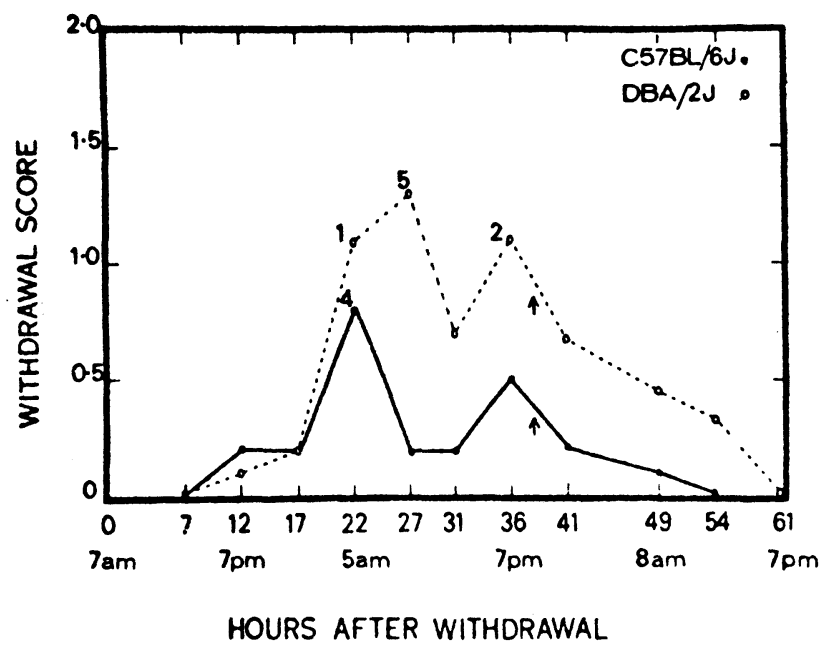

Fig. 2. Mean withdrawal scores for $\mathrm{C} 57 \mathrm{BL} / 6 \mathrm{~J}$ mice (solid circles) and DBA/2J mice (open circles) previously on PB diet (N $=10$ per strain). The numbers above the points indicate the number of animals exhibiting seizures or wild running. The arrows indicate the approximate time of death of the one animal per strain which failed to survive withdrawal. 


\section{REFERENCES}

Belknap, J. Behavioral pharmacogenetics in laboratory animals: Alcohol, barbiturates and the opiates. In J. Bruell (Ed.), Prospects on behavior genetics. New York: Russell Sage Foundation, in press.

Blagoeva, P., Longo, V., Masi, I., \& De Carolis, A. Alterations in behavior, EEG, and brain cortical GABA content following prolonged administration and subsequent withdrawal of barbital in the rat. Behavioral Biology, 1972, 7, 755-760.

Collier, H. O. J., Francis, D. L., \& Schneider, C. Modification of morphine withdrawal by drugs interacting with humoral mechanisms: Some contradictions and their interpretation. Nature, 1972, 237(5352), 220-233.

Crossland, J., \& Leonard, B. Barbiturate withdrawal convulsions in the rat. Biochemical Pharmacology, 1963, 12(supplement), 103.

Essig, C. Barbiturate withdrawal in white rats. International Journal of Neuropharmacology, 1966, 5, 103-107.

Essig, C. Barbiturate dependence. In R. Harris, W. McIsaac, \& C. Schuster (Eds.), Drug dependence. Austin: University of Texas Press, 1970.

Freund, G. Alcohol, barbiturate and bromide withdrawal syndrome in mice. In J. Mendelson and N. Mello (Eds.), Recent advances in alcoholism. Washington, D.C: U.S. Government Printing Office, 1971. Pp. 453-471.
Leonard, B. The effect of chronic administration of barbitone sodium on the behavior of the rat. International Journal of Neuropharmacology, 1967, 6, 63-70.

Leonard, B. The effect of chronic administration of sodium barbitone on chemically and electrically induced convulsions in the rat. International Journal of Neuropharmacology, 1968, 7, 463-468.

Mello, N. K. A review of methods to induce alcohol addiction in animals. Pharmacology, Biochemistry \& Behavior, 1973, 1, 89-101.

Schuster, C. R., \& Thompson, T. Self-administration of and dependence on drugs. Annual Review of Pharmacology, 1969, 9, 483-502.

Way, E. L., Loh, H. H., \& Shen, F. Morphine tolerance, physical dependence and synthesis of brain 5-hydroxytryptamine. Science, $1968,162,1290-1292$.

Waters, D., \& Okamoto, M. Increased central excitability in non-dependent mice during chronic barbital dosing. In J. Singh, L. Miller, and H. Lal (Eds.), Drug addiction: Experimental pharmacology. Mt. Kisco, N.Y: Future, 1972. Waters, D., \& Okamoto, M. Barbital dose and treatment duration: Effects on the incidence and severity of physical dependence. Federation Proceedings, 1973, 32, 681.

(Received for publication September 20, 1973; accepted September 27, 1973.) 